\title{
ORIGINAL
}

\section{VALORACIÓN EPIDEMIOLÓGICA DE LA LINFADENITIS TUBERCULOSA EN UN DISTRITO DE BARCELONA: PROPUESTA DE ALGORITMO DIAGNÓSTICO}

\author{
Silvia Aguilar-Duran y Francesca Sánchez Martínez.
}

Servicio de Medicina Interna-Enfermedades Infecciosas. Hospital del Mar, Parc de Salut Mar. Barcelona.

\section{RESUMEN}

Fundamentos: Barcelona ha experimentado un cambio en su demografía que ha afectado la epidemiología local de la linfadenitis tuberculosa (LT). El objetivo del estudio es conocer los factores actualmente asociados a LT en un distrito de Barcelona con una incidencia media de TB superior a 50 casos por 10.000 habitantes/año así como plantear un algoritmo diagnóstico.

Métodos: estudio de cohortes retrospectivo de todos los casos de LT diagnosticados entre 1990 y 2009 en el Hospital del Mar de Barcelona. De acuerdo a los cambios demográficos, se establecieron dos periodos de estudio (1990-1999 y 2000-2009) y se analizaron y compararon las características sociodemográficas, clínicas y diagnósticas de los sujetos con LT para la posterior realización del algoritmo. La información se obtuvo de las encuestas epidemiológicas realizadas a los pacientes diagnosticados de LT en el Hospital del Mar y notificadas a la Agència de Salut Pública de Barcelona.

Resultados: en el primer periodo, 152 pacientes presentaron LT (siendo $73,7 \%$ autóctonos) y en el segundo 147 (siendo 70,7\% inmigrantes). En el primer periodo, el porcentaje de hombres immigrantes fue de $70,5 \%$ y $57,1 \%$ menores de 35 años, aunque en el segundo periodo se observó en autóctonos e $158,1 \%$ de mujeres y $69,8 \%$ mayores de 35 años. El porcentaje de pacientes autóctonos con VIH disminuyó de $66,9 \%$ a 44,2\% en el segundo periodo y hubo aumento de pacientes en tratamiento inmunosupresor $(9,3 \%)$. El análisis multivariante dio como resultado (OR 8,$2 ;$ IC $95 \%$ 3,4-19,8) para el uso de drogas intravenosas y OR 4,8 (IC95\% 2,7-8,3)para la inmigración como factores de riesgo a LT.

Conclusiones: los varones inmigrantes menores de 35 años procedentes de zonas endémicas de tuberculosis y los autóctonos mayores de 35 años con VIH (aunque con un menor porcentaje de coinfección que antes del año 2000) o en tratamiento inmunosupresor son los grupos con más riesgo de presentar LT en nuestro distrito.

Palabras clave: Adenitis tuberculosa, VIH. Inmigración.

Correspondencia

Silvia Aguilar-Duran

Servicio de Medicina Interna y Enfermedades Infecciosas

Hospital del Mar. Parc de Salut Mar

Passeig Marítim, 25-29. 08003 Barcelona

España

silvi_agui@hotmail.com

\section{ABSTRACT \\ Epidemiological Analysis of Tuberculous Lymphadenopathy in a District of Barce- lona: Proposal of a Diagnostic Algorithm}

Background: Barcelona (Spain) has experienced a dramatic change in its demography, which is reflected in the local epidemics of tuberculous lymphadenopathy (TL). The objective of the study is to analyze the associated risk factors to TL in a district of Barcelona with an incidence above 50 cases per 10,000 inhabitants/year, which will help to construct a diagnostic algorithm.

Methods: single-centre retrospective cohort study of all cases of TL diagnosed between 1990 and 2009. Due to the demographic changes, we analyzed 2 separate study periods (1990-1999 and 2000-2009). Sociodemographic, clinical and diagnostic features were assessed and compared between both cohorts and the algorithm was constructed with these results. Data was obtained from all the patients diagnosed with TL in Hospital del Mar (Barcelona) and was sent to the Public Health Agency of Barcelona .

Results: in the first study period, 152 patients had TL (73.7\% Spanishborn) and in the second study period 147 (70.7\% immigrants). In the first period, the percentage of male immigrants was $70.5 \%$ and $57.1 \%$ were younger than 35 years old but in the second study period, there was a $58.1 \%$ of Spanish-born female patients and $69.8 \%$ above 35 years old. The percentage of HIV co-infection decreased from $69.9 \%$ to $44.2 \%$ in the second period but use of immunosuppressive treatment increased to $9.3 \%$ in Spanish-born patients. Multivariate analysis showed intravenous drug use (OR 8.2; 95\% CI: 3.4-19.8) and immigrant status (OR 4.8; 95\%CI: $2.7-$ 8.3 ) as risk factors associated to TL.

Conclusion: male immigrants arriving from areas with high burden of TB, younger than 35 years old and Spanish-born women, older than 35 years old, with HIV infection (although with a lower proportion than before year 2000) or receiving immunosuppressive treatment, are the groups with an increased risk of TL in our district.

Keyword: Tuberculous lymphadenopathy. HIV. Immigration. 


\section{INTRODUCCIÓN}

A finales de la década de 1980 se observó un marcado aumento en la tasa de incidencia de tuberculosis (TB) en la ciudad de Barcelona ${ }^{1}$, especialmente en el distrito de Ciutat Vella, que coincidió con la epidemia creciente de la infección por el virus de la inmunodeficiencia humana (VIH) y que afectó especialmente a los usuarios de drogas intravenosas (UDI) ${ }^{2}$. La asociación tan sólida como evidente de ambas entidades llevó a incluir la búsqueda sistemática de coinfección por M. tuberculosis en la rutina asistencial de estos pacientes, la cual sigue vigente en la actualidad. Los cambios demográficos y sociosanitarios acontecidos en nuestro entorno a partir del año 2000 comportaron una caída del número de pacientes con VIH y un aumento paralelo de los casos de TB en la población inmigrante ${ }^{3}$ procedente mayoritariamente de países endémicos. Con la nueva situación demográfica, no sólo se ha confirmado que la TB ha pasado a afectar más a inmigrantes, sino que confirma que el tipo y manifestaciones clínicas de la enfermedad, habitualmente de localización pulmonar, han dejado paso a las formas extrapulmonares, siendo la forma más frecuente la linfadenopatía tuberculosa (LT) ${ }^{4}$.

La población del distrito de Ciutat Vella de Barcelona presenta una incidencia media de TB superior a 50 casos por 10.000 habitantes/año ${ }^{4}$.

El objetivo de este trabajo es conocer los factores actualmente asociados a linfadenitis tuberculosa y compararlos con los factores asociados a LT antes del año 2000 en el distrito de Ciutat Vella de Barcelona así como plantear un algoritmo diagnóstico para identificar de forma precoz a los pacientes con linfadenitis tuberculosa.

\section{MATERIAL Y MÉTODOS}

Estudio de cohortes retrospectivo de los casos de LT diagnosticados entre 1990 y
2009 en un único centro hospitalario (Hospital del Mar de Barcelona) de 455 camas.

La información se obtuvo a partir de las encuestas epidemiológicas realizadas a los sujetos diagnosticados de LT en el Hospital del Mar y notificadas a la Agència de Salut Pública de Barcelona de manera confidencial. Se registraron distintas variables para establecer el perfil clinicoepidemiológico de los casos. La información fue completada con la revisión de las historias clínicas de los pacientes incluidos en el estudio.

Se consideraron casos de LT los de pacientes en quienes se obtuvo el diagnóstico de certeza, bien por aislamiento de $M$. tuberculosis en el cultivo específico para micobacterias o mediante la detección de su ADN por reacción en cadena de la polimerasa (PCR). En todos los sujetos las muestras se obtuvieron mediante punción-aspiración con aguja fina (PAAF). Cuando no se obtuvo material suficiente se realizó biopsia ganglionar. También se consideraron casos de LT aquellos en los que se obtuvo resolución clínica con el tratamiento antituberculoso. Los pacientes en quienes se identificaron micobacterias distintas de M. tuberculosis se excluyeron del estudio.

El estudio fue dividido en 2 períodos (1990-1999 y 2000-2009). Se consideraron las siguientes variables: edad en el momento del diagnóstico, sexo, país de procedencia, presencia de factores relacionados con la exclusión social (alcoholismo, UDI y problemática social considerada como paro/sin subsidio de desempleo y/o ausencia de domicilio fijo), además de los antecedentes patológicos relacionados con el riesgo aumentado de desarrollar TB (tabaquismo, diabetes mellitus, infección por el VIH, administración de tratamiento inmunosupresor, insuficiencia renal crónica, gastrectomía). Estos factores no fueron excluyentes. No se incluyó la variable hábitos sexuales debido a que no estaba recogida en la ficha epidemiológica. 
Se registraron los síntomas y signos clínicos que presentaban los pacientes en el momento del diagnóstico junto con el antecedente de tratamiento previo (de la enfermedad o de la infección latente) y las pruebas complementarias que se llevaron a cabo para llegar al diagnóstico: la prueba de tuberculina, la radiografía de tórax y los estudios bacteriológico y anatomopatológico. Cuando la radiografía de tórax fue patológica se investigó si se había solicitado al menos una muestra de esputo para estudio de micobacterias. Los casos en que la tinción y/o el cultivo de esputo fueron positivos se excluyeron del estudio. Finalmente se recogió el tipo y la duración del tratamiento indicado así como su resultado. Se consideró conclusión satisfactoria si los pacientes se curaron clínicamente, con tratamiento completo y no satisfactoria cuando se trataba de enfermos crónicos, perdidos $\mathrm{y}$ fallecidos ${ }^{5}$.

Estudio microbiológico. La detección de M. tuberculosis se llevó a cabo mediante tinción de Ziehl-Neelsen y auramina. Una vez descontaminadas, las muestras se cultivaron en medio sólido (Löwenstein-Jensen, bioMérieux clinical diagnostics, SA). En la segunda mitad de la década de los 90 se comenzaron a realizar en paralelo los cultivos en medios sólidos (Löwenstein) y líquidos: Bactec $9000 \AA$ (Becton Dickinson Diagnostic Systems) y BacT/AlertMP (bioMérieux) que sustituyó al Bactec 9000 en 1999.

Análisis estadístico. Se realizó el análisis univariado de todas estas variables con el que se realizó el algoritmo diagnóstico. Además se llevó a cabo un análisis multivariante de las variables clínicoepidemiológicas significativas respecto la conclusión final satisfactoria. Para el estudio estadístico se utilizó el paquete SPSS versión 15.0 (SPSS Inc. 233 South Wacker Drive, Chicago, IL, EE.UU.). Para el análisis univariado de las variables cualitativas se utilizó la prueba de la chi-cuadrado clásica o de Pearson. Se realizó el análisis multivariante, expresado como Odds
Ratio (OR) con sus intervalos de confianza (IC 95\%) mediante regresión logística binaria. Los resultados se consideraron estadísticamente significativos cuando el valor de $\mathrm{p}$ fue $<0,05$.

\section{RESULTADOS}

En la tabla 1 se recogen las características clínicoepidemiológicas, diagnóstico y conclusión de los pacientes según el periodo de estudio (1990-99 y 2000-2009). En el primer periodo 152 pacientes presentaron LT. De ellos 112 eran autóctonos y 40 inmigrantes. En el segundo periodo un total de 147 presentaban LT: 43 eran autóctonos y 104 inmigrantes. En ambos periodos, el porcentaje de varones fue de $70,4 \%$ y $66,0 \%$, respectivamente, y el porcentaje de pacientes menores de 35 años del $60,5 \%$ y $53,7 \%$ respectivamente. El porcentaje de alcoholismo y UDI en el primer periodo fue del $36,2 \%$ y $39,5 \%$ y disminuyó a $13,8 \%$ y $4,8 \%$ en el segundo $(\mathrm{p}<0,01)$, aunque el porcentaje de problemática social fue del $35 \%$ en ambos periodos. En cuanto a los antecedentes patológicos, se observó un $59,2 \%$ de pacientes con infección por VIH y $57,9 \%$ de fumadores en el primer periodo $(\mathrm{p}<0,01)$ disminuyendo a $19,0 \%$ y $31,3 \%$ en el segundo periodo, respectivamente $(p<0,01)$. Hubo 8 pacientes con antecedentes de tratamiento de la infección latente y tratamiento de la enfermedad previa en la ficha epidemiológica de los casos estudiados.

Durante el primer periodo de estudio, el motivo de consulta más frecuentemente registrado fue el síndrome tóxico $(42,1 \%)$ y a partir del año 2000 la auto observación de adenopatías $(69,4 \%)(\mathrm{p}<0,01)$, aunque el $48,0 \%$ de los pacientes en el primer periodo presentaron más de un motivo de consulta y en el segundo periodo el $32,7 \%$.

El análisis multivariante identificó el uso de drogas (OR 8,2; IC 95\% 3,4-19,8) y la inmigración (OR 4,8; IC 95\% 2,7-8,3) como factores de riesgo asociados a LT. 
Tabla 1

Características clínicoepidemiológicas, diagnóstico y conclusión de los pacientes con LT según periodo de estudio

\begin{tabular}{|c|c|c|c|c|c|}
\hline & \multicolumn{3}{|c|}{$\begin{array}{l}\text { Análisis univariante } \\
\text { total }(\mathrm{n}=299)\end{array}$} & \multicolumn{2}{|c|}{$\begin{array}{c}\text { Análisis } \\
\text { multivariante }\end{array}$} \\
\hline & $\begin{array}{c}1990-99 \\
\mathrm{n}=152(\%)\end{array}$ & $\begin{array}{c}2000-09 \\
\mathrm{n}=147(\%)\end{array}$ & $\mathrm{p}$ & OR $(95 \% \mathrm{IC})$ & $\mathrm{p}$ \\
\hline $\begin{array}{l}\text { Sexo } \\
\text { - Hombres } \\
\text { - Mujeres }\end{array}$ & $\begin{array}{r}107(70,4) \\
45(29,9)\end{array}$ & $\begin{array}{l}97(66,0) \\
50(34,0)\end{array}$ & 0,45 & & \\
\hline $\begin{array}{l}\text { Edad } \\
-<35 \text { años } \\
->35 \text { años }\end{array}$ & $\begin{array}{l}92(60,5) \\
60(39,5)\end{array}$ & $\begin{array}{l}79(53,7) \\
68(46,3)\end{array}$ & 0,24 & & \\
\hline Autóctonos & $112(73,7)$ & $43(29,3)$ & $<0,01$ & & \\
\hline Inmigrantes & $40(25,8)$ & $104(70,7)$ & $<0,01$ & $4,8(2,7-8,3)$ & $<0,01$ \\
\hline $\begin{array}{l}\text { Factores de exclusión social } \\
\text { - Alcoholismo }\end{array}$ & $55(36,2)$ & $20(13,8)$ & $<0,01$ & & \\
\hline - Usuarios de drogas inyectadas & $60(39,5)$ & $7(4,8)$ & $<0,01$ & $8,2(3,4-19,8)$ & $<0,01$ \\
\hline - Problemática social & $54(35,5)$ & $52(35,4)$ & 1,0 & & \\
\hline $\begin{array}{l}\text { Antecedentes patológicos } \\
\text { - Diabetes mellitus } \\
\text { - Virus inmunodeficiencia humana } \\
\text { - Insuficiencia renal crónica } \\
\text { - Tabaquismo } \\
\text { - Tratamiento inmunosupresor } \\
\text { - Gastrectomía }\end{array}$ & $\begin{array}{r}5(3,3) \\
90(59,2) \\
0 \\
88(57,9) \\
2(1,3) \\
2(1,3)\end{array}$ & $\begin{array}{r}8(5,4) \\
28(19,0) \\
2(1,4) \\
46(31,3) \\
5(3,4) \\
0\end{array}$ & $\begin{array}{r}0,40 \\
<0.01 \\
0,24 \\
<0,01 \\
0,27 \\
0,49\end{array}$ & & \\
\hline $\begin{array}{l}\text { Clínica inicial } \\
\text { - Adenopatías } \\
\text { - Síndrome tóxico } \\
\text { - Fiebre } \\
\text { - Tos y expectoración }\end{array}$ & $\begin{array}{l}60(39,5) \\
64(42,1) \\
58(38,2) \\
48(31,6)\end{array}$ & $\begin{array}{r}102(69,4) \\
46(31,3) \\
34(23,1) \\
16(10,9)\end{array}$ & $\begin{array}{r}<0,01 \\
0,05 \\
<0,01 \\
<0,01\end{array}$ & & \\
\hline $\begin{array}{l}\text { Quimioprofilaxis o tratamiento de la } \\
\text { enfermedad previa }\end{array}$ & $2(1,3)$ & $6(4,1)$ & 0,16 & & \\
\hline $\begin{array}{l}\text { Diagnóstico } \\
\text { - Prueba de tuberculina positiva } \\
\text { - Microscopía directa positiva } \\
\text { - Cultivo positivo } \\
\text { - PCR positiva } \\
\text { - Anatomía patológica } \\
\text { - Radiografía tórax patológica }\end{array}$ & $\begin{array}{r}43(46,2) \\
22(14,6) \\
111(73,5) \\
0 \\
147(96,7) \\
87(58,4)\end{array}$ & $\begin{array}{r}94(94,0) \\
26(18,3) \\
94(66,2) \\
4(66,7) \\
121(82,3) \\
48(34,0)\end{array}$ & $\begin{array}{r}<0,01 \\
0,43 \\
0,20 \\
0 \\
<0,01 \\
<0,01\end{array}$ & & \\
\hline $\begin{array}{l}\text { Conclusión final } \\
\text { Satisfactoria } \\
\text { No satisfactoria }\end{array}$ & $\begin{array}{l}87(57,2) \\
65(42,8)\end{array}$ & $\begin{array}{r}141(95,9) \\
6(8,5)\end{array}$ & $<0,01$ & & \\
\hline
\end{tabular}

La prueba diagnóstica con mayor rendimiento en el primer periodo fue la anatomía patológica $(96,7 \%)$. Se observó también un $58,4 \%$ de radiografías de tórax patológicas durante el primer periodo con cultivo de esputo negativo. Durante el segundo periodo, se utilizó la PCR sobre muestra histológica en 6 pacientes, y resultó positiva en 4 de ellos. 
Tabla 2

Características clínicoepidemiológicas según lugar de procedencia

\begin{tabular}{|c|c|c|c|c|c|c|}
\hline & \multicolumn{3}{|c|}{$1990-99(\mathrm{n}=152)$} & \multicolumn{3}{|c|}{$2000-2009(n=147)$} \\
\hline & $\begin{array}{c}\text { Autóctonos } \\
(\mathrm{n}=112)\end{array}$ & $\begin{array}{c}\text { Inmigrantes } \\
(\mathrm{n}=40)\end{array}$ & $\mathrm{p}$ & $\begin{array}{c}\text { Autóctonos } \\
(\mathrm{n}=43)\end{array}$ & $\begin{array}{c}\text { Inmigrantes } \\
(\mathrm{n}=104)\end{array}$ & $\mathrm{p}$ \\
\hline $\begin{array}{l}\text { Sexo } \\
\text { - Hombres } \\
\text { - Mujeres }\end{array}$ & $\begin{array}{l}79(70,5) \\
33(29,5)\end{array}$ & $\begin{array}{l}28(70,0) \\
12(30,0)\end{array}$ & 1,0 & $\begin{array}{l}18(41,9) \\
25(58,1)\end{array}$ & $\begin{array}{l}79(76,0) \\
25(24,0)\end{array}$ & $<0,01$ \\
\hline $\begin{array}{l}\text { Edad } \\
-<35 \text { años } \\
->35 \text { años }\end{array}$ & $\begin{array}{l}64(57,1) \\
48(42,9)\end{array}$ & $\begin{array}{l}28(70,0) \\
12(30,0)\end{array}$ & 0,18 & $\begin{array}{l}13(30,2) \\
30(69,8)\end{array}$ & $\begin{array}{l}66(63,5) \\
38(36,5)\end{array}$ & $<0,01$ \\
\hline $\begin{array}{l}\text { Factores de exclusión social } \\
\text { - Alcoholismo } \\
\text { - Usuarios de drogas inyectadas } \\
\text { - Problemática social }\end{array}$ & $\begin{array}{l}43(38,4) \\
53(47,3) \\
38(33,9)\end{array}$ & $\begin{array}{r}12(30,0) \\
7(17,5) \\
16(40,0)\end{array}$ & $\begin{array}{r}0,44 \\
<0,01 \\
0,56\end{array}$ & $\begin{array}{l}9(20,9) \\
5(11,6) \\
5(11,6)\end{array}$ & $\begin{array}{r}11(10,8) \\
2(1,9) \\
47(45,2)\end{array}$ & $\begin{array}{r}0,11 \\
0,02 \\
<0,01\end{array}$ \\
\hline $\begin{array}{l}\text { Antecedentes patológicos } \\
\text { - Diabetes mellitus } \\
\text { - Virus inmunodeficiencia humana } \\
\text { - Insuficiencia renal crónica } \\
\text { - Tabaquismo } \\
\text { - Tratamiento inmunosupresor } \\
\text { - Gastrectomía }\end{array}$ & $\begin{array}{r}2(1,8) \\
78(69,6) \\
0 \\
70(62,5) \\
2(1,8) \\
2(1,8)\end{array}$ & $\begin{array}{r}3(7,5) \\
12(30,0) \\
0 \\
18(45,0) \\
0 \\
0\end{array}$ & $\begin{array}{r}0,11 \\
<0,01 \\
0 \\
0,06 \\
1,0 \\
1,0\end{array}$ & $\begin{array}{r}4(9,3) \\
19(44,2) \\
0 \\
17(39,5) \\
4(9,3) \\
0\end{array}$ & $\begin{array}{r}4(3,8) \\
9(8,7) \\
2(1,9) \\
29(27,9) \\
1(1,0) \\
0\end{array}$ & $\begin{array}{r}0,23 \\
<0,01 \\
1,0 \\
0,17 \\
0,02\end{array}$ \\
\hline $\begin{array}{l}\text { Clínica inicial } \\
\text { - Adenopatías } \\
\text { - Síndrome tóxico } \\
\text { - Fiebre } \\
\text { - Tos y expectoración }\end{array}$ & $\begin{array}{l}44(39,3) \\
50(44,6) \\
50(44,6) \\
38(33,9)\end{array}$ & $\begin{array}{r}16(40,0) \\
14(35,0) \\
8(20,0) \\
10(25,0)\end{array}$ & $\begin{array}{r}0,85 \\
0,35 \\
<0,01 \\
0,32\end{array}$ & $\begin{array}{r}30(69,8) \\
14(32,6) \\
10(23,3) \\
7(16,3)\end{array}$ & $\begin{array}{r}72(69,2) \\
32(30,8) \\
24(23,1) \\
9(8,7)\end{array}$ & $\begin{array}{r}1,0 \\
0,84 \\
1,0 \\
0,24\end{array}$ \\
\hline Quimioprofilaxis o tratamiento de la enfermedad previa & $1(0,9)$ & $1(2,5)$ & 0,45 & $3(7,0)$ & $3(2,9)$ & 0,35 \\
\hline $\begin{array}{l}\text { Diagnóstico: } \\
\text { - Prueba de tuberculina positiva } \\
\text { - Microscopía directa positiva } \\
\text { - Cultivo positivo } \\
\text { - PCR positiva } \\
\text { - Anatomía patológica } \\
\text { - Radiografía tórax patológica }\end{array}$ & \begin{tabular}{|r|}
$25(36,8)$ \\
$16(14,4)$ \\
$81(73,0)$ \\
0 \\
$109(97,3)$ \\
$70(63,1)$
\end{tabular} & $\begin{array}{r}18(72,0) \\
6(15,0) \\
30(75,0) \\
0 \\
38(97,4) \\
17(44,7)\end{array}$ & $\begin{array}{r}<0,01 \\
1,0 \\
1,0 \\
\\
0,25 \\
0,05\end{array}$ & $\begin{array}{r}19(79,2) \\
13(31,0) \\
29(69,0) \\
0 \\
37(90,2) \\
15(35,7)\end{array}$ & $\begin{array}{r}75(98,7) \\
13(13,0) \\
65(65,0) \\
4(66,7) \\
84(92,3) \\
33(33,3)\end{array}$ & $\begin{array}{r}<0,01 \\
0,01 \\
0,70 \\
\\
0,73 \\
0,84\end{array}$ \\
\hline $\begin{array}{l}\text { Conclusión final satisfactoria } \\
\text { Conclusión no satisfactoria }\end{array}$ & \begin{tabular}{|l|}
$59(52,7)$ \\
$53(47,3)$
\end{tabular} & $\begin{array}{l}28(70,0) \\
12(30,0)\end{array}$ & 0,04 & $\begin{array}{r}40(93,0) \\
3(7,0)\end{array}$ & $\begin{array}{r}101(97,1) \\
3(2,9)\end{array}$ & 0,35 \\
\hline
\end{tabular}

Los países de procedencia de los pacientes inmigrantes eran Pakistán (69), India (8), Marruecos (8), Filipinas (6), Ecuador (5), China (4), Bangladesh (3), Nigeria (2), Senegal (2), Brasil (2), Argelia (1), Burkina Faso (1), Gambia (1), Guinea Ecuatorial (1), Bolivia (1), Colombia (1), Cuba (1), Panamá (1), Perú (1), Argentina (1), Chile (1), Venezuela (1). p corresponde al análisis univariante.

En la tabla 2 se hallan las características clínicoepidemiológicas según el lugar de procedencia y el periodo de estudio. De los 299 casos analizados, 144 (48\%) habían nacido fuera de España y procedían de 3 continentes distintos, siendo el subcontinente indio la región que más casos aportó (66\%).
En el segundo periodo se observó en los pacientes autóctonos el $58,1 \%$ de mujeres y $69,8 \%$ de pacientes mayores de 35 años $(\mathrm{p}<0,01)$. El porcentaje de pacientes autóctonos con infección por VIH fue del $44,2 \%$ y de UDI el $11,6 \%$, aunque la problemática social fue significativamente mayor en inmigrantes $(45,2 \%)(p<0,01)$. El tratamiento inmunosupresor fue del 
$9,3 \%$ en autóctonos y del $1,0 \%$ en inmigrantes $(\mathrm{p}=0,02)$.

En la tabla 3 se resume el tipo y la duración del tratamiento. Durante el periodo de estudio el $57,1 \%$ de los pacientes que tuvieron una conclusión satisfactoria fueron tratados con 4 fármacos [(isoniacida $(\mathrm{H})$, rifampicina $(\mathrm{R})$, pirazinamida $(\mathrm{Z})$ y etambutol (E)] durante 6 meses (2HRZE/4HR), el $56,8 \%$ de los pacientes que no obtuvieron una conclusión satisfactoria tomaron el tratamiento con 3 fármacos durante 6 meses (2HRZ/4HR). No se observaron diferencias estadísticamente significativas en los resultados del tratamiento cuando los pacientes se trataron durante 9 meses.

\section{Tabla 3}

Tratamiento administrado a los pacientes con linfadenitis tuberculosa

\begin{tabular}{|l|c|c|c|}
\hline & $\begin{array}{c}\text { CFS } \\
(\mathrm{n}=224)\end{array}$ & $\begin{array}{c}\text { CFNS } \\
(\mathrm{n}=74)\end{array}$ & $\mathrm{p}$ \\
\hline 2HRZ/4HR, n (\%) & $75(33,5)$ & $42(56,8)$ & $<0,01$ \\
\hline 2HRZE/4HR, n (\%) & $128(57,1)$ & $20(27,0)$ & $<0,01$ \\
\hline 2HRZ/7HR, n (\%) & $7(3,1)$ & $4(5,4)$ & 0,47 \\
\hline 2HRZE/7HR, n (\%) & $14(6,3)$ & $3(4,1)$ & 0,57 \\
\hline 18-24 Meses, n (\%) & 0 & $5(6,8)$ & $<0,01$ \\
\hline
\end{tabular}

CFS:conclusión final satisfactoria. CFNS: conclusión final no satisfactoria. HRZ: isoniazida + rifampicina + pirazinamida. HRZE:isoniazida + rifampicina + pirazinamida + etambutol. HR: isoniacida, rifampicina.

En cuanto a las resistencias del tratamiento antituberculoso, no se realizaron estudios de sensibilidad de forma sistemática durante el primer período, por lo que sólo se encuentran disponibles los datos de resistencia en el segundo periodo de estudio. Se observaron $7(4,7 \%)$ casos de resistencia a la isoniacida, $5(3,4 \%)$ a la estreptomicina, 2 $(1,4 \%)$ a la rifampicina y $2(1,4 \%)$ a la pirazinamida.

A partir de las características clínicoepidemiológicas (lugar de procedencia, serología positiva para VIH y tratamiento inmunosupresor en pacientes autóctonos) y diag- nósticas (resultado de la PAAF) se elaboró el algoritmo diagnóstico que motiva este trabajo (figura 1).

\section{DISCUSIÓN}

El presente estudio refleja que los varones nacidos fuera de España, procedentes de países con alta incidencia de TB y los sujetos autóctonos mayores de 35 años y receptores de tratamientos inmunosupresores son dos colectivos de riesgo para desarrollar LT en nuestra población, especialmente en el momento presente en el que la coinfección por VIH ligada al consumo de drogas muestra una clara tendencia a disminuir. Es importante remarcar que el aumento significativo de pacientes autóctonos en tratamiento inmunosupresor se basa en un escaso número de pacientes (4), lo que hace que haya que ser cautos con la interpretación de estos resultados. Por otro lado, el porcentaje de casos VIH positivos y el uso de drogas intravenosas, aunque ha disminuido de forma notable del primer periodo al segundo, sigue siendo elevado, especialmente entre los casos autóctonos. El estudio multivariante confirmó la inmigración y el uso de drogas intravenosas como factores de riesgo asociados a LT. Otro aspecto a destacar es el aumento del porcentaje de mujeres respecto al de varones. En la figura 1 se realizó un algoritmo diagnóstico con los resultados hallados.

En el informe realizado por la Agència de Salut Pública de Barcelona del año $2009^{6}$, la prevalencia en autóctonos se mantenía en los mismos niveles $(9 \%)$ pero el aumento de los casos en inmigrantes $(26,7 \%)$ condicionó el aumento del total de casos de LT $(17,6 \%)$ y de TB extrapulmonar $(27,3 \%)$. Estos datos son también comparables con los de otros estudios realizados, tanto en el continente europeo ${ }^{7,8}$, donde existe un patrón epidemiológico parecido al de España, como fuera de Europa 9 . 
Figura 1

Algoritmo para el diagnóstico precoz de linfadenitis tuberculosa

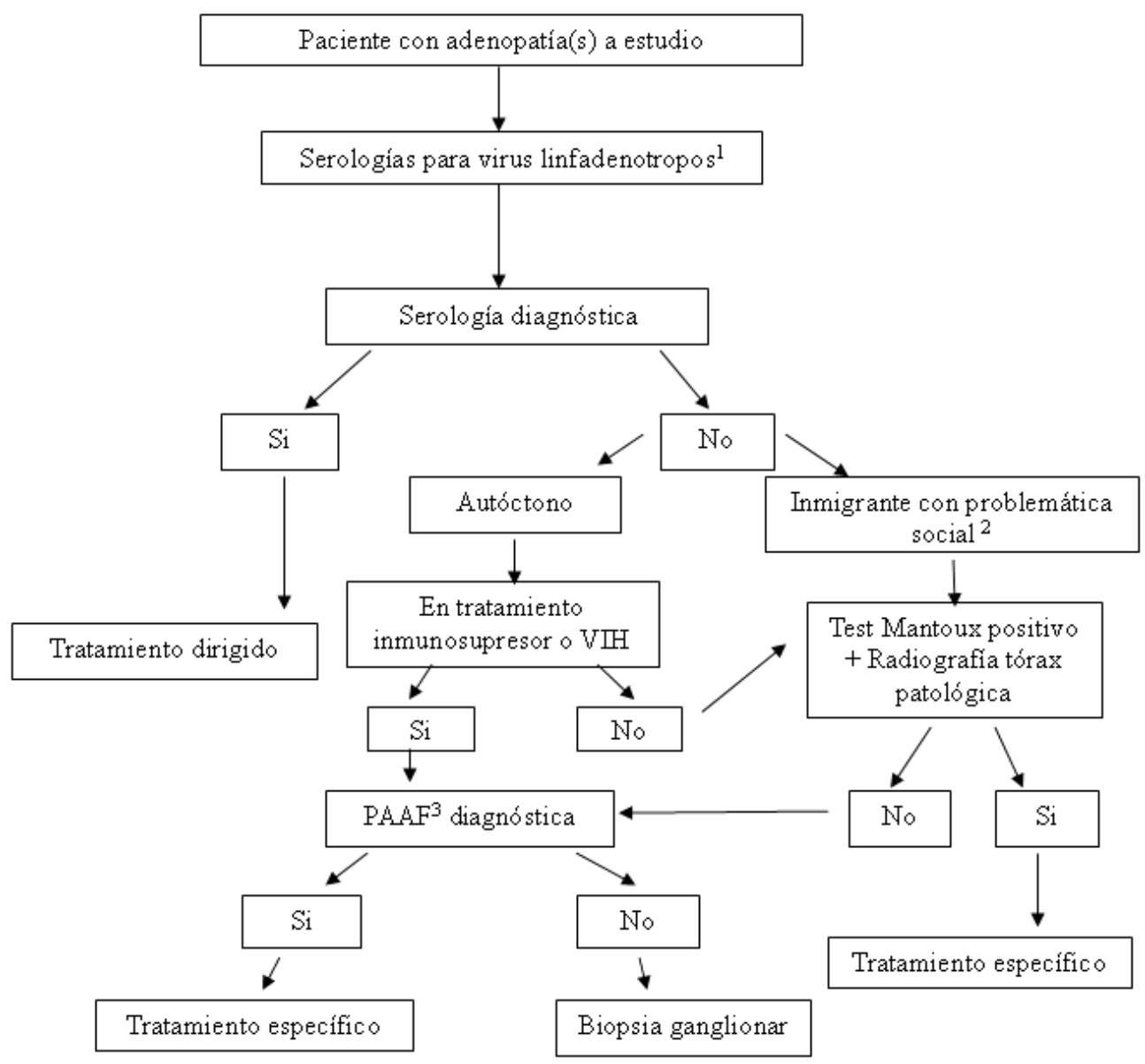

1 En los pacientes autóctonos sin factores de riesgo conocidos para tuberculosis (como estar en tratamiento inmunosupresor) es más frecuente que las adenopatías sean de etiología inflamatoria-inespecífica o producidas por infecciones bacterianas o virales, no siempre diagnosticadas por las exploraciones complementarias convencionales de laboratorio. Se aconseja complementar el estudio inicial de las adenopatías con un hemograma y un frotis de sangre periférica y con hemocultivos, en caso de acompañarse de fiebre elevada, sin otra causa aparente.

2 De acuerdo al documento de consenso para el control y prevención de la TB en inmigrantes ${ }^{22}$ cualquier paciente procedente de un país de alta endemia tuberculosa debería, al entrar en contacto con alguna de las prestaciones del Sistema Nacional de Salud, ser estudiado para descartar infección tuberculosa latente y, eventualmente, enfermedad activa.

3 PAAF: punción-aspiración con aguja fina. Excepto en lesiones muy inflamatorias y accesibles, es preferible realizarla con control ecográfico y enviar una parte a Anatomía Patológica y estudio microbiológico. La inoculación directa del material obtenido en frascos de hemocultivo para micobacterias aumenta la rentabilidad diagnóstica en la LT. 
En nuestra serie, los países que aportan mayor número de pacientes son principalmente los del subcontinente indio, que mantiene un gran aflujo de inmigrantes en Cataluña, especialmente en la ciudad de Barcelona. Estas cifras no son idénticas al resto de España, ya que cada área presenta un patrón demográfico distinto. A modo de ejemplo, en nuestro estudio no se registraron pacientes procedentes de países del Este de Europa con LT.

Se ha debatido ampliamente cuál sería el método más adecuado para el cribado y control de la TB en inmigrantes que llegan desde países con alta endemia a países con endemias bajas y muy bajas. A pesar de que se han llevado a cabo estudios en los que se realizaban radiografías de tórax y pruebas de tuberculina de manera indiscriminada a toda la población inmigrante, se ha observado que estas medidas no son de gran impacto en materia de salud pública y tampoco son coste-efectivas ${ }^{10}$. Se ha demostrado que la estrategia más adecuada para el control de la TB continúa siendo el diagnóstico precoz, el tratamiento de los casos activos y la detección de los casos con infección latente con riesgo de progresión ${ }^{11}$. En nuestro estudio se observó que los casos diagnosticados en el primer período (1990-99) eran autóctonos en su mayoría y estaban asociados, principalmente, a la infección por el VIH relacionada con el consumo de drogas. Aunque a partir de 2000 los casos de VIH disminuyeron debido a la disminución de UDI e introducción de la terapia antirretroviral de gran actividad (TARGA), sigue observándose una mayor frecuencia de coinfección en pacientes autóctonos. Esta evidencia pone de manifiesto que, a pesar del mejor control de ambas infecciones, no se puede obviar su interrelación y siempre hay que realizar una serología para descartar la infección por VIH en pacientes diagnosticados de $\mathrm{TB}^{12}$. También en el segundo período (2000-09) se observaron más factores asociados a precariedad social en inmigrantes diagnosticados de LT. Ello puede ser debido no sólo al rápido aumento de población inmigrante que por sí mismo conlleva cierto grado de exclusión social ${ }^{13}$, sino también a la disminución de los factores de riesgo entre los autóctonos que favorecen la marginalidad social ${ }^{14}$. Es remarcable también el aumento de LT en pacientes autóctonos en tratamiento inmunosupresor. Está bien documentada la mayor susceptibilidad a la TB de los pacientes en tratamiento inmunosupresor, concretamente se describen casos de LT tras iniciar tratamiento biológico ${ }^{15}$, por lo que es indispensable descartar tanto la infección latente como la enfermedad tuberculosa activa antes de iniciarlos ${ }^{16}$.

Con respecto a los métodos diagnósticos, hay que destacar que la baciloscopia y el cultivo de las muestras presentaron un rendimiento más bajo que en otros estudios realizados en $\mathrm{LT}^{17}$, por lo que la histología fue de gran utilidad. Consideramos que puede deberse más a la técnica para la obtención de la muestra (la PAAF a ciegas podría ser menos rentable que la guiada por ecografía) que a la baja carga bacilar, pero también al procesamiento de las muestras en el laboratorio. La utilización de los medios líquidos (Bactec $9000 \mathrm{y}$, especialmente, BacT/Alert) en el segundo período ha demostrado mayor sensibilidad para la recuperación de $M$. tuberculosis que el medio sólido de Löwenstein ${ }^{18}$. Se intentó limitar el estudio exclusivamente a los casos de LT, excluyendo los que presentaron una radiografía de tórax anormal y con baciloscopia positiva pero es posible que una parte no despreciable de ellos presentaran infección pulmonar a pesar de la bacteriología negativa y con LT como localización secundaria, lo que introduce un sesgo en la selección en nuestra muestra.

Con el cambio demográfico, el tipo de tratamiento y la duración es una de las decisiones más importantes a considerar. Por un lado, existe el problema del cumpli- 
miento, ligado a la exclusión social y también relacionado con la inmigración por motivos económicos ${ }^{19,20}$, y por otro lado el aumento creciente de las resistencias a los fármacos de primera línea, especialmente la isoniacida, que amenaza actualmente también a los de segunda. Debido a que los resultados respecto a las resistencias de fármacos son escasos en nuestro estudio, únicamente se puede inferir en la necesidad de hacerlos de forma sistemática. Sin embargo, a diferencia de lo que ocurre para la TB pulmonar o extrapulmonar de otras localizaciones, existen investigaciones que muestran menores niveles de resistencias a fármacos en casos de $\mathrm{LT}^{21}$. En este trabajo, los datos sobre los resultados satisfactorios del tratamiento muestran que es mejor la pauta con 4 fármacos que con 3 durante 6 meses, lo que podría traducir la mayor efectividad de las pautas cuádruples en los casos más complejos, como los coinfectados por el VIH, con la limitación de obviar otras causas. Es interesante observar que los casos de inmigrantes presentan mayor conclusión satisfactoria del tratamiento que los autóctonos. Es posible que se deba a que se realiza mayor supervisión o seguimiento del tratamiento en este colectivo o a que la información se recoge de manera más correcta.

En resumen, este estudio, basado en la epidemiología de la TB en un área urbana de alta incidencia, muestra un incremento de los casos de TB de localización ganglionar en varones jóvenes procedentes de zonas endémicas y en mujeres autóctonas mayores de 35 años y con menor porcentaje de infección por VIH que en los años 90. A pesar de la utilización del TARGA para el tratamiento de la infección por VIH y la aplicación de los programas contra la drogadicción, ambos colectivos contribuyen a mantener la incidencia de LT marcadamente por encima del objetivo del programa de control ${ }^{16}$ por lo que se aconseja descartar esta patología ante cualquier consulta para estudio de adenopatías.

\section{AGRADECIMIENTOS}

A los miembros del servicio de Medicina Interna del Hospital del Mar de Barcelona.

\section{BIBLIOGRAFÍA}

1. Orcau A, Cayla JA, Martinez JA. Epidemiología actual de la tuberculosis. Programas de prevención y control. Enferm Infecc Microbiol Clin. 2011. 29 Suppl 1:2-7.

2. Cayla JA, Galdós-Tangüis H, Jansà JM, García de Olalla P, Brugal T, Pañella H. Evolución de la tuberculosis en Barcelona (1987-1995). Influencia del virus de la inmunodeficiencia humana y de las medidas de control. Med Clin (Barc). 1998. 111(16): 608-15.

3. Valles X, Sánchez F, Pañella H, García de Olalla P, Jansà JM, Caylà JA. Tuberculosis importada: una enfermedad emergente en países industrializados. Med Clin (Barc). 2002. 118(10): 376-8.

4. Orcau A, García de Olalla P, Caylà JA. La tuberculosi a Barcelona. Informe 2009. Programa de prevenció i control de la tuberculosi a Barcelona. Disponible en: www.aspb.cat/quefem/docs/Tuberculosi_2009.pdf

5. Cayla JA, Camionero JA, Rey R, Lara N, Vallés X, Galdós-Tanguïs $\mathrm{H}$ et al. Current status of treatment completion and fatality among tuberculosis patients in Spain. Int J Tuberc Lung Dis. 2004. 8(4): 458-64.

6. La tuberculosis en Cataluña en el año 2009. Programa de prevención y control de la tuberculosis en Cataluña. Subdirección general de vigilancia y respuesta a emergencias de salud pública. Barcelona: Generalitat de Catalunya; 2010.

7. Arce Arnaez A, Iñigo Martínez J, Cabello Ballestero L, Burgoa Arenales M. Tuberculosis e inmigración en un área sanitaria de Madrid. Situación epidemiológica y evolución en la década 1994-2003. Med Clin (Barc). 2005. 125(6): 210-2.

8. Seersholm N, Wilcke T. [Diagnosis of extrapulmonary tuberculosis is a challenge]. Ugeskr Laeger. 2011. 173(12): 886-9.

9. Cadmus SI, Oluwasola AO, Okolo CA, Bethrand AF. Pattern of tuberculous lymphadenitis diagnosed by fine needle aspiration cytology at the University College Hospital, Ibadan, Nigeria. Afr J Med Med Sci. 2010. 39(3): 193-7.

10. Dasgupta K, Menzies D. Cost-effectiveness of tuberculosis control strategies among immigrants and refugees. Eur Respir J. 2005. 25(6): 1107-16. 
11. Santin Cerezales M, Navas Elorza E. Tuberculosis en poblaciones especiales. Enferm Infecc Microbiol Clin. 2011. 29 Suppl 1: 20-5.

12. Branson BM, Handsfield HH, Lampe MA, Janssen RS, Taylor AW, Lyss SB et al. Revised recommendations for HIV testing of adults, adolescents, and pregnant women in health-care settings. MMWR Recomm Rep. 2006. 55(RR-14): 1-17; quiz CE1-4.

13. Tezanos JF. Inmigración y exclusión social. Papeles de Econ Esp . 2003; 225-237.

14. Jansa JM, Serrano J, Caylà JA, Vidal R, Ocaña I, Español T. Influence of the human immunodeficiency virus in the incidence of tuberculosis in a cohort of intravenous drug users: effectiveness of anti-tuberculosis chemoprophylaxis. Int J Tuberc Lung Dis. 1998. 2(2): $140-6$.

15. Velasco J, Gonzalez S. Adenitis tuberculosa tras tratamiento con éxito de hepatitis C. Enferm Infecc Microbiol Clin. 2011. 29(8): p. 631.

16. Ravn P. [Screening for tuberculosis infection prior to medical therapy]. Ugeskr Laeger. 2011. 173(12): 893-6.

17. Khan AH, Sulaiman SA, Muttalif AR, Hassali MA, Khan TM. Tuberculous lymphadenitis at Penang General Hospital, Malaysia. Med Princ Pract. 2011. 20(1): 80-4.

18. Pfyffer GE, Cieslak C, Welscher HM, Kissling P, Rüsch-Gerdes S. Rapid detection of mycobacteria in clinical specimens by using the automated BACTEC $9000 \mathrm{MB}$ system and comparison with radiometric and solid-culture systems. J Clin Microbiol. 1997. 35(9): 2229-34.

19. Cayla JA, Rodrigo T, Ruiz-Manzano J, Caminero JA, Vidal R, García JM et al. Tuberculosis treatment adherence and fatality in Spain. Respir Res. 2009. 10: 121.

20. Anibarro L, Casas S, Paz-Esquete J, Gonzalez L, Pena A, Guerra MR et al. Treatment completion in latent tuberculosis infection at specialist tuberculosis units in Spain. Int J Tuberc Lung Dis. 2010. 14(6): 701-7.

21. Lai CC, Liu WL, Tan CK, Huang YC, Chung KP, Lee MR et al. Differences in drug resistance profiles of Mycobacterium tuberculosis isolates causing pulmonary and extrapulmonary tuberculosis in a medical centre in Taiwan, 2000-2010. Int J Antimicrob Agents. 2011. 38(2): 125-9.
22. Grupo de trabajo de los talleres de 2001 y 2002 de la Unidad de Investigación en tuberculosis de Barcelona. Prevención y control de la tuberculosis importada. Med Clin (Barc). 2003;121(14): 549-57. 